\title{
Milrinone is superior to epinephrine as treatment of myocardial depression due to ropivacaine in pigs
}

\author{
Steven Neustein MD, \\ Ian Sampson MD, \\ Ivan Dimich MD, \\ Howard Shiang MD, \\ Juvonen Tatu MD
}

Purpose: To determine whether milrinone is more effective than epinephrine in the resuscitation of ropivacaine induced cardiotoxicity in pigs.

Methods: Arterial, pulmonary, and LVdP/dt catheters were placed in 12 anesthetized, intubated and mechanically ventilated pigs. They received ropivacaine iv to cardiovascular toxicity: 50\% decrease in LVdP/dt, cardiac output and mean arterial pressure (MAP). Group I $(\mathrm{n}=6)$ was treated with $100 \mu \mathrm{g} \cdot \mathrm{kg}^{-1}$ milrinone iv, and Group II $(n=6)$ received $0.5 \mathrm{mg}$ epinephrine iv. Resuscitation was successful if cardiac output returned to baseline, and MAP reached $80 \%$ of baseline.

Results: After ropivacaine, MAP decreased from $88 \pm 7$ to $49 \pm 8 \mathrm{mmHg}(P<0.05)$, CO decreased from 2.8 \pm 0.4 to $1.2 \pm 0.2 \mathrm{~L} \cdot \mathrm{min}^{-1}(P<.05)$, HR decreased from $103 \pm 8$ to $74 \pm 7$ beats $\mathrm{min}(P<0.05)$ and LVdp/dt decreased from $1950 \pm 130$ to $755 \pm 125 \mathrm{mmHg}(P<0.05)$. The LV EDP increased from $5 \pm 1$ to $8 \pm 1$ $\mathrm{mmHg}(P<0.05)$ and SVR from 2317 to $3000 \pm 120$ dynes $\cdot \mathrm{sec}^{-1} \cdot \mathrm{cm}^{-5}$. Electrocardiogram changes included increases in the QTU interval and QRS duration. In all animals, milrinone restored MAP, CO, SV, HR, and dP/dt to baseline and no animal developed arrhythmias. In contrast, epinephrine produced severe hypertension and tachycardia. There was no improvement in CO or SV, and SVR increased. Epinephrine caused A-V dissociation and ventricular arrhythmias in three animals.

Conclusion: Milrinone, was more successful than epinephrine in resuscitating anesthetized pigs from ropivacaine-induced cardiovascular toxicity.

Objectif : Déterminer si la milrinone est plus efficace que l'épinéphrine au moment de réanimer des porcs victimes d'une cardiotoxicité induite par la ropivacaïne.

Méthode : Des cathéters artériels, pulmonaires et ventriculaires gauches (dP/dtVG) ont été mis en place chez 12 porcs anesthésiés, intubés et sous ventilation mécanique. Ils ont reçu de la ropivacaïne iv qui a provoqué la cardiotoxicité manifestée par : une baisse de $50 \%$ dP/dtVG, du débit cardiaque (DC) et de la pression artérielle moyenne (PAM). Le groupe I $(n=6)$ a été traité avec $100 \mu \mathrm{g} \cdot \mathrm{kg}^{-1}$ de milrinone iv et le groupe II $(n=6)$ avec 0,5 mg d'épinéphrine iv. La réanimation était réussie lorsque le DC revenait aux valeurs de base et que la PAM atteignait $80 \%$ des valeurs de base.

Résultats : Après l'administration de la ropivacaïne, la PAM a chuté de $88 \pm 7$ à $49 \pm 8 \mathrm{mmHg}(P<0,05)$, le DC de 2,8 $\pm 0,4$ à I,2 $\pm 0,2 \mathrm{~L} \cdot \mathrm{min}^{-1}(P<0,05)$, la FC de $103 \pm 8$ to $74 \pm 7$ battements $\cdot \min (P<0,05)$ et $\mathrm{dP} / \mathrm{dtVG}$ de $1950 \pm 130$ à $755 \pm 125 \mathrm{mmHg}(P<0,05)$. La pression télédiastolique du VG a augmenté, passant de $5 \pm 1$ à $8 \pm 1 \mathrm{mmHg}(P<0,05)$ et la résistance vasculaire périphérique (RVP) de 2317 à $3000 \pm 120$ dynes $\cdot \mathrm{S}^{-1} \cdot \mathrm{cm}^{-5}$. Les changements à l'électrocardiogramme comprenaient des augmentations de l'intervalle QTU et de la durée de QRS. Chez tous les animaux, la milrinone a ramené la PAM, le DC, le débit systolique (DS), la FC et dP/dt aux valeurs de base et aucun animal n'a présenté d'arythmie. Par ailleurs, l'épinéphrine a produit une sévère hypertension et de la tachycardie. II n'y a pas eu d'amélioration du DC ou du DS et la RVP a augmenté. L'épinéphrine a aussi causé une dissociation AV et des arythmies ventriculaires chez trois animaux.

Conclusion : La milrinone a été plus efficace que l'épinéphrine pour la réanimation de porcs anesthésiés qui ont subi une cardiotoxicité provoquée par de la ropivacaïne.

From the Departments of Anesthesiology and Cardiothoracic Surgery, The Mount Sinai Medical Center, New York, NY, USA. Address correspondence to: Steven Neustein MD, Box 1010, Department of Anesthesiology, Mount Sinai Medical Center, 1 Gustave L. Levy Place, New York, NY 10029-6574, USA. Phone: 212-241-7467; Fax: 212-426-2009; E-mail: steven_neustein@smtplink.mssm.edu Paper presented at the IARS 72nd Clinical and Scientific Congress 1998. Accepted for Publication July 20, 2000. 
W E investigated the effectiveness of milrinone in the resuscitation of anesthetized pigs given ropivacaine intravenously. Milrinone is a selective cAMP phosphodiesterase inhibitor, which enhances cardiac contractility and increases cardiac output.

We studied ropivacaine because it is a relatively new local anesthetic that may replace bupivacaine in the future due to its reduced toxicity. Clinical experience regarding its cardiotoxicity and treatment is very limited.

The purpose of this study was to determine whether the administration of milrinone is superior to epinephrine in resuscitation of ropivacaine induced cardiotoxicity in pigs.

Methods

After approval of the protocol by the Institutional Animal Investigation Committee, Yorkshire albino pigs weighing $25-30 \mathrm{~kg}$ were anesthetized with 30 $\mathrm{mg} \cdot \mathrm{kg}^{-1}$ pentobarbital $i v$ and anesthesia was maintained with pentobarbital infusion at $4 \mathrm{mg} \cdot \mathrm{kg}^{-1} \cdot \mathrm{hr}^{-1}$. Tracheal intubation was performed and then mechanical ventilation instituted to maintain the arterial blood gases at $\mathrm{pH} 7.35 \pm 0.01$ and the $\mathrm{PaCO}_{2}$ at 35 to $40 \mathrm{mmHg}$. A heating lamp maintained the esophageal temperature between $37^{\circ} \mathrm{C}$ and $39^{\circ} \mathrm{C}$.

Normovolemia was maintained by infusing lactated Ringer's solution via an intravenous cannula at the rate of $4 \mathrm{~mL} \cdot \mathrm{kg}^{-1} \cdot \mathrm{hr}^{-1}$. A 14 -gauge polyurethane cannula was inserted into the femoral artery to measure aortic pressure and to obtain intermittent arterial blood gas and electrolyte measurements. A thermodilution pulmonary catheter was placed in the pulmonary artery via the femoral vein. A left-sided thoracotomy was performed and the pericardium excised. A Millar (Millar Instruments, Houston, Texas) microtipped pressure transducer was inserted into the left ventricle by way of the left atrial appendage to measure end-diastolic pressure and the first derivative of left ventricular pressure $(\mathrm{LVdP} / \mathrm{dt})$.

\section{Measurements}

The following variables were recorded - heart rate, systolic, diastolic and mean arterial pressure, right atrial pressure, mean pulmonary artery pressure and pulmonary artery capillary wedge pressure. Left ventricular systolic and diastolic pressure and $\mathrm{LVdP} / \mathrm{dt}$ were measured and recorded. Cardiac output was measured in triplicate by thermodilution. An electrocardiograph (ECG) was continuously monitored and results were examined for arrhythmias, conduction defects, and ST Segment changes.

\section{Experimental protocol}

After the 30 min stabilization period, hemodynamic measurements were obtained. Ropivacaine $0.5 \%$ was administered by a syringe infusion pump, ( 2 $\mathrm{mg} \cdot \mathrm{kg}^{-1} \cdot \mathrm{min}^{-1}$ ) until there was a $50 \%$ decrease in $\mathrm{LVdP} / \mathrm{dt}$, cardiac output and MAP.

At the same time, to mimic the respiratory conditions after clinical seizures which often render patients apneic, the animals were made apneic for $90 \mathrm{sec}$ by disconnecting the ventilator from the endotracheal tube. After $90 \mathrm{sec}$ apnea, ABG tensions were measured, and the lungs were ventilated with oxygen $100 \%$. Animals were then randomized to one of two groups. The animals in Group I $(\mathrm{n}=6)$ were treated with $100 \mu \mathrm{g} \cdot \mathrm{kg}^{-1}$ milrinone $i v$. If there was no improvement after five minutes, milrinone was repeated. Those in Group II $(\mathrm{n}=6)$ received $0.5 \mathrm{mg}$ epinephrine, and the dose was repeated if there was no improvement after five minutes. The animals were considered to have been successfully resuscitated if the cardiac outputs improved to baseline, and the mean arterial pressure reached $80 \%$ of the baseline value.

Statistical Analyses were performed using two way repeated measure ANOVA. $P<0.05$ was considered statistically significant.

Results

The hemodynamic data obtained during the control period, ropivacaine infusion and therapeutic intervention with either milrinone (Group I) or epinephrine (Group II) are shown in Tables I and II.

No animal received more than one dose of the study drug.

Compared with base line, ropivacaine infusion (average dose $7.2 \pm 0.5 \mathrm{mg} \cdot \mathrm{kg}^{-1}$ ) caused, in both groups, decreases in MAP, cardiac output, stroke volume, heart rate, $\mathrm{LVdP} / \mathrm{dt}$ and increases in LVEDP and SVR $(P<0.05)$. The electrocardiographic changes included increases of the QT interval and QRS duration. The duration of QRS and QT interval increased in both groups following injection of ropivacaine. In Group I, the QRS interval increased from control $50 \pm 4$ to $66 \pm 7 \mathrm{msec}$. The QT interval increased from control $210 \pm 8$ to $281 \pm 10 \mathrm{msec}$. In Group II QRS interval increased from control $52 \pm 5$ to $67 \pm 4 \mathrm{msec}$ and the QT interval from control 212 \pm 6 to $283 \pm 9 \mathrm{msec}$. Despite electrophysiologic changes induced by ropivacaine, no spontaneous arrhythmias occurred in any animal.

In all animals, administration of milrinone (average dose $100 \mu \mathrm{g} \cdot \mathrm{kg}^{-1}$ ) rapidly restored MAP, cardiac output, stroke volume, heart rate and $\mathrm{LVdP} / \mathrm{dt}$ to baseline. SVR and LVEDP decreased (Table I). No animal 
TABLE I

\begin{tabular}{|c|c|c|c|c|c|c|}
\hline \multirow[b]{2}{*}{ Parameters } & \multicolumn{3}{|c|}{ After Ropivacaine } & \multicolumn{3}{|c|}{ After Milrinone } \\
\hline & Baseline & $1 \mathrm{~min}$ & $3 \mathrm{~min}$ & $1 \mathrm{~min}$ & $3 \mathrm{~min}$ & $5 \mathrm{~min}$ \\
\hline HR bpm & $103 \pm 8$ & $81 \pm 9$ & $74 \pm 7^{*}$ & $98 \pm 9 \dagger$ & $108 \pm 7 \dagger$ & $111 \pm 8 \dagger$ \\
\hline MAP mmHg & $88 \pm 7$ & $72 \pm 5^{*}$ & $49 \pm 8^{*}$ & $76 \pm 6 \dagger$ & $83 \pm 5^{*}$ & $88 \pm 6 \dagger$ \\
\hline $\mathrm{CO} \mathrm{L} \cdot \mathrm{min}^{--1}$ & $2.8 \pm 0.4$ & $1.3 \pm 0.2^{*}$ & $1.2 \pm 0.2^{*}$ & $2.6 \pm 0.3$ & $2.9 \pm 0.4 \dagger$ & $2.9 \pm 0.6 \dagger$ \\
\hline SV ml.beat ${ }^{-1}$ & $27 \pm 2$ & $16 \pm 2^{*}$ & $16.0 \pm 3^{*}$ & $26 \pm 2 \dagger$ & $28 \pm 1 \dagger$ & $27 \pm 2 \dagger$ \\
\hline $\mathrm{LVdP} / \mathrm{dt} \mathrm{mmHg}$ & $1950 \pm 130$ & $780 \pm 120^{*}$ & $755 \pm 125^{*}$ & $1750 \pm 140 \dagger$ & $2050 \pm 130 \dagger$ & $2100 \pm 90 \dagger$ \\
\hline LVEDP mmHg & $5 \pm 1$ & $7 \pm 1^{*}$ & $8 \pm 1^{*}$ & $6 \pm 1 \dagger$ & $6 \pm 1 \dagger$ & $6 \pm 1 \dagger$ \\
\hline SVR dyne.sed ${ }^{-1}$ & $2317 \pm 120$ & $4123 \pm 130 *$ & $3000 \pm 120$ & $2184 \pm 95$ & $2289 \pm 125$ & $2344 \pm 105$ \\
\hline
\end{tabular}

Mean \pm SP

${ }^{*} P<0.05$ vs baseline

$\dagger P<0.05$ vs after ropivacaine $(3 \mathrm{~min})$

TABLE II

\begin{tabular}{|c|c|c|c|c|c|c|}
\hline \multirow[b]{2}{*}{ Parameters } & \multicolumn{3}{|c|}{ After Ropivacaine } & \multicolumn{3}{|c|}{ After Epinephrine } \\
\hline & Baseline & $1 \mathrm{~min}$ & $3 \mathrm{~min}$ & $1 \mathrm{~min}$ & $3 \mathrm{~min}$ & $5 \mathrm{~min}$ \\
\hline HR bpm & $106 \pm 6$ & $84 \pm 7$ & $76 \pm 8^{*}$ & $163 \pm 21 \dagger$ & $175 \pm 18 \dagger$ & $173 \pm 21 \dagger$ \\
\hline MAP mmHg & $92 \pm 7$ & $78 \pm 5$ & $57 \pm 8 *$ & $140 \pm 16 \dagger$ & $155 \pm 13 \dagger$ & $131 \pm 15 \dagger$ \\
\hline $\mathrm{CO} \mathrm{L} \cdot \mathrm{min}^{-1}$ & $3.1 \pm 0.6$ & $1.1 \pm 0.1^{*}$ & $1.0 \pm 0.2^{*}$ & $1.4 \pm 0.3^{*}$ & $1.9 \pm 0.2^{*}$ & $2.1 \pm 09^{*} \dagger$ \\
\hline SV ml.beat ${ }^{-1}$ & $30 \pm 2$ & $13.1 \pm 1^{*}$ & $13.2 \pm 3^{*}$ & $8.5 \pm 3^{*} \dagger$ & $10.8 \pm 2^{*}$ & $12.1 \pm 3^{*}$ \\
\hline $\mathrm{LvdP} / \mathrm{dt} \mathrm{mmHg}$ & $1820 \pm 110$ & $760 \pm 130^{*}$ & $745 \pm 90^{*}$ & $1650 \pm 130 \dagger$ & $1950 \pm 120 \dagger$ & $1970 \pm 130 \dagger$ \\
\hline LVEDP mmHg & $4 \pm 1$ & $7 \pm 1^{*}$ & $8 \pm 05^{*}$ & $7.1 \dagger$ & $7 \pm 1 \dagger$ & $6 \pm 1$ \\
\hline SVR dyn·sec & $2175 \pm 130$ & $5309 \pm 125^{*}$ & $4320 \pm 130 *$ & $7657 \pm 135^{*} \dagger$ & $6231 \pm 100 * \dagger$ & $4761 \pm 125^{*}$ \\
\hline
\end{tabular}

Mean \pm SD

${ }^{*} P<0.05$ vs baseline

$\dagger P<0.05$ vs after ropivacaine $(3 \mathrm{~min})$

developed serious cardiac arrhythmias, but there was no improvement in QT and QRS duration.

In contrast to milrinone, administration of $0.5 \mathrm{mg}$ epinephrine iv precipitated severe hypertension and tachycardia. Although LVdP/dt increased, there was no improvement in cardiac output or stroke volume, and the SVR increased. Epinephrine induced A-V dissociation and ventricular arrhythmias in three animals. One pig demonstrated ventricular tachycardia that degenerated to terminal ventricular fibrillation. Arterial $\mathrm{PO}_{2}, \mathrm{PCO}_{2}$ and $\mathrm{pH}$ did not change significantly during the experiment in either group, except during the short period of apnea.

All animals in both groups, except the animal which developed ventricular fibrillation, had stable blood pressure $30 \mathrm{~min}$ after treatment without need for additional pharmacologic support.

\section{Discussion}

Ropivacaine (Naropin ${ }^{\circledR}$, ASTRA Pharmacuetical, Sweden) is a new amide local anesthetic that is structurally similar to bupivacaine and has similar local anesthetic therapeutic effects. Although ropivacaine has been reported to have less cardiotoxicity than bupivacaine, cardiovascular complications may still occur after inadvertent intravenous administration or following absorption. ${ }^{1,2}$

There has been much interest in the untoward cardiovascular effects of potent long acting anesthetics. ${ }^{3-6}$ However, few detailed studies have determined whether animals could be successfully resuscitated. ${ }^{7}$ Feldman et al. ${ }^{7}$ studied the treatment of acute cardiovascular toxicity from bupivacaine and ropivacaine in dogs. Treatment included increasing doses of $0.5 \mathrm{mg}$ epinephrine, bretylium, direct current cardioversion, and cardiac massage. In that study, there was still a high mortality rate, although it was less in the ropivacaine group. Several dogs in the ropivacaine group developed ventricular fibrillation after epinephrine administration. In conclusion, these authors suggested that other inotropes or vasopressor drugs may be preferable to epinephrine for cardiovascular resuscitation from local anesthetic toxicity.

Butterworth et al. ${ }^{8}$ demonstrated in vitro that bupivacaine inhibit both basal and epinephrine stimulated cAMP production. They postulated that local 
anesthetic inhibition of cAMP involves beta-receptors in the myocardium, contributing to the difficulty of resuscitation following induced cardiovascular toxicity. In this study, a high dose of epinephrine was unsuccessful in increasing cAMP production in the presence of bupivacaine toxicity.

Milrinone 9,10 is a selective cAMP phosphodiesterase inhibitor. It increases the intracellular concentration of cAMP in the heart by preventing its breakdown, and acts independently of beta adrenergic receptors. Milrinone improves myocardial contractility, increases cardiac output and produces peripheral vasodilatation. All these attributes suggest that milrinone could be a better choice than epinephrine in the treatment of cardiovascular toxicity induced by ropivacaine.

In our study, the infusion of ropivacaine resulted in severe and sustained hypotension, and decreases in $\mathrm{LVdP} / \mathrm{dt}$ and cardiac output, indicating myocardial depression. However, in contrast to bupivacaine, ropivacaine did not induce cardiac arrhythmias. Similar findings were reported by Santos et al. ${ }^{11}$ in sheep although no attempts were made to resuscitate animals.

In our study, milrinone reversed myocardial depression induced by ropivacaine. Mean arterial pressure, cardiac output, stroke volume, LVdP/dt and LVEDP returned to baseline in all animals within two to three minutes. Milrinone did not produce tachycardia, hypertension, or cardiac arrhythmias. In contrast to milrinone, epinephrine induced severe tachycardia, hypertension and arrhythmias, and failed to improve myocardial function, although $\mathrm{LVdP} / \mathrm{dt}$ did increase.

We did not attempt to establish dose-response relationships with either milrinone or epinephrine. Rather, the intent was to use these drugs to establish whether cardiotoxicity induced by ropivacaine could be reversed. A limitation of our study is that pregnant animals were not used and, therefore, the results cannot be extrapolated to the pregnant human patients.

It is possible that in awake animals hypoxia and acidosis due to grand mal seizure may exacerbate the cardiovascular toxicity of ropivacaine. We attempted to reproduce the respiratory effect of a seizure by making the animals apneic for $90 \mathrm{sec}$ at the start of the ropivacaine injection. After the $90 \mathrm{sec}$ apnea, the lungs were ventilated with oxygen $100 \%$. These experimental conditions are similar to the clinical situations that occur during a seizure, when patients become apneic and are ventilated with oxygen. Most of our animals were hypoxic following the apnea but they improved immediately after ventilation. ${ }^{7}$

During our experiment, fluids were given in amounts adequate to maintain right-atrial pressure between 4 and $10 \mathrm{~mm} \mathrm{Hg}$. It is possible that had we not monitored the right atrial pressure constantly, we might not have given an adequate amount of fluid. The success of our resuscitation might have been diminished if the animals were allowed to become hypovolemic. General anesthesia may have altered the toxic profile of the local anesthetic drugs. For example, ventricular arrhythmias, which have been reported in humans and conscious animals occur less frequently, in anesthetized dogs which had received large doses of bupivacaine $i v$. In addition, the cardiovascular depression produced by ropivacaine is less marked than that produced by bupivacaine and, therefore, may be more easily managed. ${ }^{7}$

In summary, milrinone, was more successful in resuscitating anesthetized pigs with cardiovascular toxicity induced by ropivacaine. The general anesthetic may have had a protective effect against the stimulation of the sympathetic nervous system.

\section{Acknowledgment}

The authors would like to express their appreciation to Helen Phillips for the preparation of this paper. The study was financed with departmental funds, and with no outside grant money.

\section{References}

1 Ruetsch $\Upsilon A$, Fattinger KE, Borgeat A Ropivacaineinduced convulsions and severe cardiac dysrhythmias after sciatic block. Anesthesiology 1999; 90: 1784-6.

2 Abouleish EI, Elias M, Nelson C Ropivacaine-induced seizure after extradural anaesthesia. Br J Anaesth 1998; 80: 843-4.

3 Nancarrow C, Rutten AJ, Runciman WB, et al. Myocardial and cerebral drug concentrationsand the mechanisms of death after fatal intravenous doses of lidocaine, bupivacaine and ropivacaine in the sheep. Anesth Analg 1989; 69: 276-83.

4 Reiz S, Häggmark S, Johansson G, Nath $S$. Cardiotoxicity of ropivacaine - a new amide local anaesthetic agent. Acta Anaesthesiol Scand 1989; 33: 93-8.

5 Moller R, Covino BG Cardiac electrophysiologic properties of bupivacaine and lidocaine compared with those of ropivacaine, a new amide local anesthetic. Anesthesiology 1990; 72: 322-9.

6 Rutten AJ, Nancarrow C, Mather LE, Ilsley AH, Runciman WB, Upton RN. Hemodynamic and central nervous system effects of intravenous bolus doses of lidocaine, bupivacaine and ropivacaine in sheep. Anesth Analg 1989; 69: 291-9.

7 Feldman HS, Arthur G, Pitkanen M, Hurley R, Doucette AM, Covino BG Treatment of acute systemic toxicity after the rapid intravenous injection of ropiva- 
caine and bupivacaine in the conscious dog. Anesth Analg 1991; 73: 373-83.

8 Butterworth JF IV, Brownlow RC, Leith JP, Prielipp $R C$, Cole LR Bupivacaine inhibits cyclic-3, 5- adenosine monophosphate production. A possible contributing factor to cardiovascular toxicity. Anesthesiology 1993; 79: 88-85.

9 Jaski BE, Fifer MA, Wright RF, Braunwald E, Colucci WS. Positive inotropic and vasodilator actions of milrinone in patients with severe congestive heart failure. Dose-response relationships and comparison to nitroprusside. J Clin Invest 1985; 75: 643-9.

10 Colucci WS, Wright RF, Jaski BE, Fifer MA, Braunwald $E$. Milrinone and dobutamine in severe heart failure: differing hemodynamic effects and individual patient responsiveness. Circulation 1986; 73(SupplIII): 175-83.

11 Santos AC, Arthur GR, Pederson H, Morishima HO, Finster M, Covino BG Systemic toxicity of ropivacaine during ovine pregnancy. Anesthesiology 1991; 75: 137-41. 